\title{
Desenvolvendo e Aplicando Dinâmicas do Jogo Digital Body no Ensino de Fisiologia Humana para Estudantes de uma Escola Pública
}

\author{
Victor Sarinho $^{1}$, Carolina Cerqueira $^{1}$, Érica Granjeiro ${ }^{1}$, Gutemberg Borges $^{1}$, \\ ${ }^{1}$ Universidade Estadual de Feira de Santana (UEFS) \\ Feira de Santana- Bahia - Brasil \\ vsarinho@uefs.br, cerqueira.carolina@gmail.com, \\ ericag@uefs.br, gutem.borges@gmail.com
}

\begin{abstract}
Nowadays, there is a level of difficulty to understand the concepts of Human Physiology (HP) in the classroom. This article describes obtained results with the development and application of the digital version of the Body game for teaching HP in a public school. For this, the game development and application methodologies are presented, as well as a detailed description of the game validation process. As obtained results, the gains of competitiveness, interaction and fun on the part of the students with the use of this tool were perceptible, allowing to the Body the capacity to offer a viable environment for the innovation in HP teaching-learning at classroom.
\end{abstract}

Resumo. Atualmente, existe um nível de dificuldade quanto à compreensão de conceitos de Fisiologia Humana (FH) em sala de aula. Este artigo descreve os resultados obtidos com o desenvolvimento e a aplicação da versão digital do jogo Body para o ensino de FH em turmas de uma escola pública. Nesse contexto, são apresentadas as metodologias de desenvolvimento e de aplicação do jogo, bem como uma descrição detalhada do processo de validação do mesmo. Dentre os resultados obtidos, foram perceptiveis os ganhos de competitividade, interação e diversão por parte dos alunos com o uso desta ferramenta, permitindo ao Body a capacidade de oferecer um ambiente para a inovação do ensino-aprendizagem de FH em sala de aula.

\section{Introdução}

Partindo de uma reflexão sobre o sistema educacional brasileiro, percebe-se a necessidade de mudança e o reencontro da escola pública na representação de um lugar próprio para a construção de algo novo, de modo a expandir as potencialidades humanas e a garantir a emancipação do coletivo [Krawczyk 2013]. Como parte desta mudança, tem-se na construção de ambientes de aprendizagem adequados e qualificados um dos grandes desafios encontrados pelas instituições de ensino em geral [Borges et al. 2016].

Trabalhos prévios relatam a importância da inserção da Fisiologia Humana (FH) na educação básica [da Rosa et al. 2013], a qual ajuda na formação crítica do cidadão e proporciona um conhecimento amplo do funcionamento do corpo humano, sendo assim fundamental para a manutenção da saúde e do bem estar do ser humano 
VII Congresso Brasileiro de Informática na Educação (CBIE 2018)

Anais do XXIX Simpósio Brasileiro de Informática na Educação (SBIE 2018)

[Campos et al. 2003]. No entanto, muitas vezes estes conteúdos são trabalhados de maneira superficial ou não são bem compreendidos pelos alunos, seja por falta de materiais didáticos que auxiliem no ensino, ou por dificuldades encontradas pelos próprios estudantes no processo de aprendizagem.

Neste sentido, os jogos educacionais são capazes de se tornarem auxiliares importantes do processo de ensino e aprendizagem, onde o aluno tem a chance de aprender de forma mais ativa, dinâmica e motivadora [Savi and Ulbricht 2008]. Mais ainda, a aplicação de jogos digitais educacionais permitem uma maior motivação e uma melhor apropriação dos conceitos estudados por parte dos estudantes adolescentes [Borges et al. 2016], os quais permanecem longos períodos totalmente empenhados nos desafios e fantasias destes artefatos de mídia [Savi and Ulbricht 2008].

Este trabalho apresenta os resultados obtidos com o desenvolvimento e a aplicação de uma versão digital do jogo Body [Borges et al. 2016] em uma escola pública. Tratase de um jogo que utiliza mecânicas clássicas de jogos de tabuleiro no ensino de $\mathrm{FH}$, permitindo a aplicação de dinâmicas diferenciadas em sala de aula, capazes de estimular os alunos a construir um processo de aprendizagem de forma colaborativa e ativa.

\section{Metodologia}

A construção do jogo digital Body foi ancorada na participação de especialistas tanto da área de Biologia como da área de Computação. Seu processo de desenvolvimento se baseou nas seguintes etapas: especificação de requisitos, design do jogo digital, construção do jogo, e a validação preliminar com especialistas. A especificação de requisitos foi baseada na análise das regras e elementos do jogo físico. Nesta etapa, os requisitos do jogo foram documentados informalmente a partir de análises iniciais de partidas realizadas no jogo físico, as quais eram feitas tanto participando como um jogador como visualizando externamente outros jogarem. Posteriormente, os requisitos do jogo foram documentados de modo mais acurado, aliando as discussões com os orientadores e professores da equipe de Biologia aos registros informais anteriormente realizados [Borges et al. 2016].

Para a etapa de construção do jogo, elaborou-se o design das interfaces e a implementação do jogo em uma versão desktop capaz de ser jogada por todos os participantes em um único computador. Sua codificação se deu através do Godot, um motor de jogo aberto que permite o desenvolvimento rápido de interfaces complexas de uma maneira compartilhada com designers e animadores [Linietsky et al. 2014]. Como resultado, o Godot possibilitou a programação das funcionalidades do jogo digital Body, bem como a inserção e a modelagem de sprites representativos do respectivo jogo (Figura 1).

Para validação do jogo digital produzido, efetuou-se uma revisão da versão alfa corrente com a equipe desenvolvedora do jogo físico, em conjunto com os orientadores e professores envolvidos neste trabalho. Este processo consistiu em apresentar e comparar a jogabilidade, os controles, a mecânica, o ambiente e a interface da versão digital produzida com a versão física previamente existente. Como resultado, semelhanças com o jogo físico foram rapidamente identificadas e avaliadas como positivas, uma vez que o jogo físico foi anteriormente validado por especialistas de Biologia. Diferenças encontradas, como o uso do mouse para realizar ataques e o uso do teclado para responder questões, ficaram por conta da adaptação digital aplicada no jogo.

Dinâmicas de grupo em sala de aula com os estudantes do Ensino Médio de uma 
VII Congresso Brasileiro de Informática na Educação (CBIE 2018)

Anais do XXIX Simpósio Brasileiro de Informática na Educação (SBIE 2018)

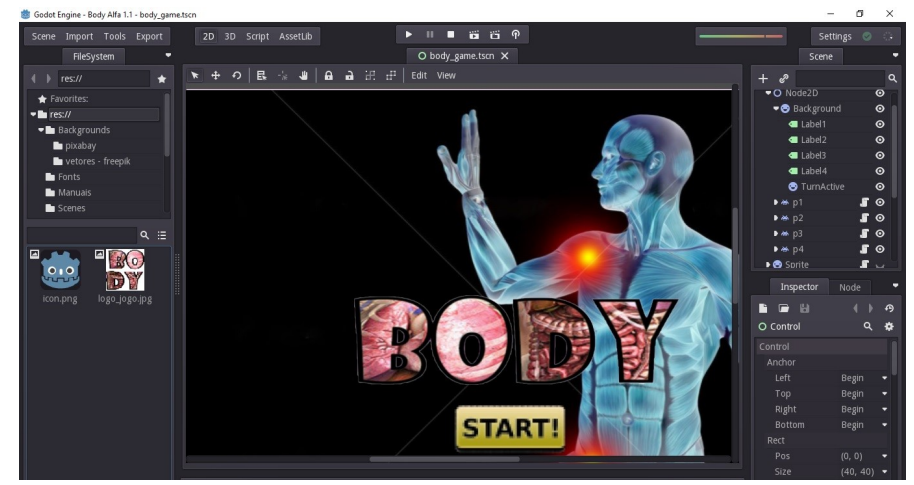

Figura 1. Ambiente de produção Godot para o jogo digital Body.

escola pública também foram aplicadas para fins de validação do jogo digital Body. Nestas dinâmicas, 4 grupos de alunos eram formados em cada turma para disputarem qual deles iria acertar mais questões e com isso ganhar a disputa. Cada grupo escolhia uma cor entre 4 possíveis e indicava em cada rodada qual adversário iria atacar. O grupo atacado tinha 1 minuto para tentar acertar a questão e não perder o órgão atacado. O tempo de cada dinâmica era aplicado conforme a duração da aula da respectiva turma participante.

A escolha das turmas para a aplicação do jogo digital foi relacionada ao conteúdo trabalhado em sala de aula nas disciplinas de Ciências e de Biologia. A Figura 2 ilustra uma das dinâmicas realizada com o jogo digital Body em uma das turmas avaliadas.
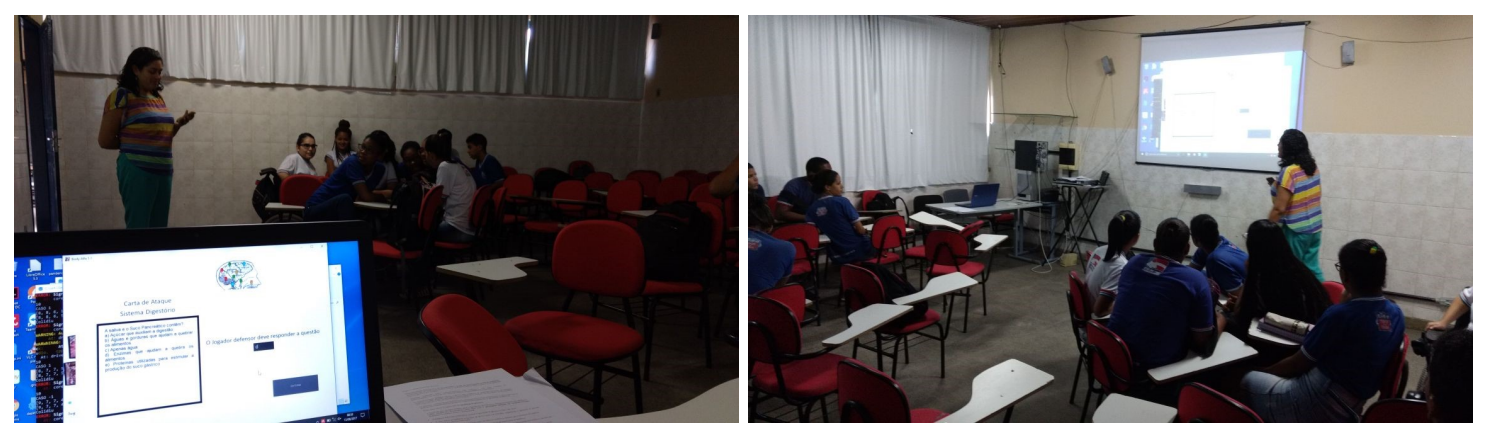

Figura 2. Validação do jogo digital Body com estudantes do terceiro ano do Ensino Médio de uma escola pública.

Para fins de verificação e validação do jogo digital, também foi aplicado um questionário de usabilidade [Lund 2001] em cada turma avaliada. Trata-se de um questionário que se preocupa em verificar quão satisfatória foi a experiência do usuário em utilizar o jogo proposto. Para tal, são aplicadas 30 questões com respostas em uma escala de 1 a 7 , sendo 1 discordando muito e 7 concordando muito, referentes a utilidade (questões 1 a 8), facilidade de usar (questões 9 a 19), facilidade de aprender (questões 20 a 23) e satisfação (questões 24 a 30) do software investigado.

Com relação a verificação da aprendizagem adquirida pelos alunos com a utilização do jogo digital Body, foram aplicados pré e pós testes avaliativos, nos quais os alunos tinham que responder 12 questões similares às que eles encontraram durante a aplicação do jogo digital. Ambos os testes de avaliação possuíam as mesmas perguntas, porém foram aplicados em períodos diferentes, com um intervalo de aproximadamente 
VII Congresso Brasileiro de Informática na Educação (CBIE 2018)

Anais do XXIX Simpósio Brasileiro de Informática na Educação (SBIE 2018)

1-2 meses entre ambos. O pré teste foi realizado uma semana antes da aplicação do jogo, e o pós teste aproximadamente 1 mês depois da aplicação do jogo.

\section{Resultados e Discussões}

Com relação ao jogo digital produzido, alguns elementos foram simplificados em comparação com o jogo físico, tais como cartas objetivo e sistemas orgânicos trabalhados. Isto se deve ao fato do jogo ser executado em um único computador, sendo assim inviável esconder os objetivos de conquista de um jogador dos demais jogadores adversários. Assim, o objetivo final do jogo se dá com a conquista da maioria ou de todos os sistemas orgânicos a depender do desempenho de cada equipe durante a aplicação do jogo digital em sala de aula. Para fins de ilustração, a Figura 3 apresenta uma das telas principais que dão base a dinâmica em sala de aula aplicada com o jogo digital, neste caso a tela de uma carta de ataque a ser respondida por um grupo participante da aplicação do jogo.

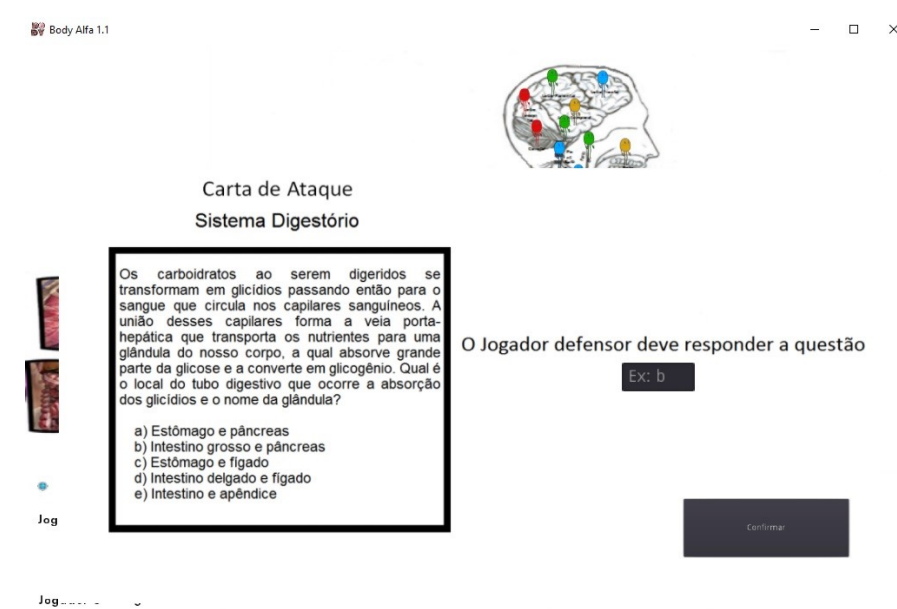

Figura 3. Tela de carta de ataque do jogo digital Body.

Com relação a aplicação dos questionários de avaliação de usabilidade, estes foram coletadas em 2 turmas que utilizaram o jogo desenvolvido, sendo a primeira turma formada por 19 alunos de uma turma do $8^{\circ}$ ano do ensino fundamental, e a segunda turma formada por 26 alunos do $2^{\circ}$ ano do ensino médio. Os resultados das respostas foram distribuídos horizontalmente em quantidades de concordância e discordância de acordo com o número de cada questão no respectivo questionário, e verticalmente com base no somatório das respostas obtidas pelas turmas analisadas conforme as categorias de usabilidade avaliadas pelo questionário (Figura 4). Respostas consideradas inválidas, sem marcação, com mais de uma marcação, ou com marcação errada foram indicadas como Resposta Não Aplicável (RNA). Como resultado, em ambas as turmas foi possível observar a grande maioria das respostas concordando com a utilidade, facilidade de uso, facilidade de aprendizagem e satisfação apresentadas pelo jogo digital desenvolvido.

\section{Conclusões e Trabalhos Futuros}

Este trabalho apresentou o desenvolvimento e a aplicação do jogo digital Body para o ensino de FH para estudantes de uma escola pública. Para tal, justificou-se a importância 
VII Congresso Brasileiro de Informática na Educação (CBIE 2018)

Anais do XXIX Simpósio Brasileiro de Informática na Educação (SBIE 2018)

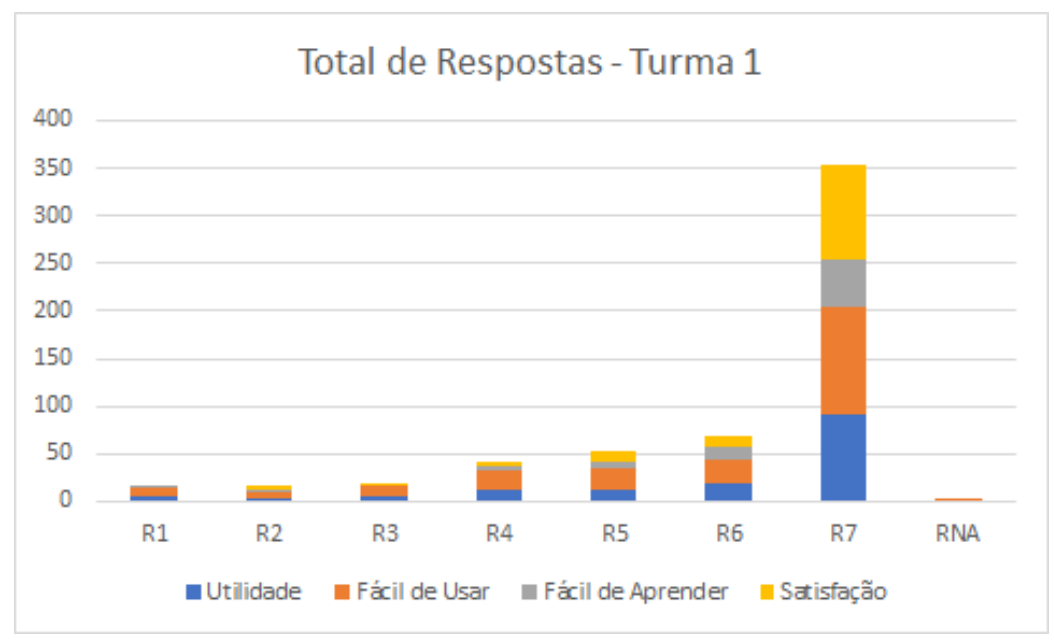

Figura 4. Total de respostas obtidas na Turma 1 avaliada.

do ensino de FH na escola pública, em conjunto com a descrição da metodologia de desenvolvimento e a abordagem de validação do jogo digital proposto.

Com relação a aplicação da versão digital do jogo em sala de aula, apesar das limitações impostas pela infraestrutura de TI encontrada na escola pública, percebeu-se ganhos efetivos de competitividade, interação e diversão por parte dos alunos. Como resultado, tem-se no jogo digital Body uma ferramenta diferenciada e de fácil utilização e atualização para o ensino de $\mathrm{FH}$, levando inclusive a reflexões futuras sobre novos materiais e métodos capazes de serem utilizados para motivar estudantes a obterem melhores resultados no aprendizado de Biologia dentro da escola pública.

\section{Referências}

Borges, G. A., Lima, C. O. C., Granjeiro, E. A., Sarinho, V. T., and Bittencourt, R. A. (2016). Body: Um jogo digital educacional de tabuleiro na area de fisiologia humana. In Proceedings of SBGames, 2016. XV SBGames, pages 412-420. SBC.

Campos, L. M. L., Bortoloto, T. M., and Felício, A. K. C. (2003). A produção de jogos didáticos para o ensino de ciências e biologia: uma proposta para favorecer a aprendizagem. Caderno dos núcleos de Ensino, 3548.

da Rosa, L. S., Gonçalves, R., Rodrigues, T., Fagundes, F. M., Tieppo, K., Isoton, M., da Silva Ribeiro, P., Carpes, F. P., Mello, E. M. B., and Mello-Carpes, P. B. (2013). Difusão da fisiologia através da capacitação de docentes da educação básica. Revista Ciência em Extensão, 9(2):128-140.

Krawczyk, N. (2013). Reflexão sobre alguns desafios do ensino médio no brasil hoje. Cadernos de pesquisa, 41(144):752-769.

Linietsky, J., Manzur, A., and Community, G. (2014). Godot docs. http://docs.godotengine.org/. Accessed: 2016-10-14.

Lund, A. M. (2001). Measuring usability with the use questionnaire12. Usability interface, $8(2): 3-6$.

Savi, R. and Ulbricht, V. R. (2008). Jogos digitais educacionais: benefícios e desafios. RENOTE, 6(1). 